\title{
DEFINICIJE I EMPIRIJSKE ŠEME PRANJA NOVCA
}

\section{Predrag Vukadinović}

Univerzitet Singidunum, Beograd, Srbija
Korespondencija: Predrag Vukadinović

e-mail:

pvukadinovic@singidunum.ac.rs

\begin{abstract}
Apstrakt:
Ubrzani razvoj ekonomije, uvođenje novih informaciono-telekomunikacionih tehnologija, razvoj finansijskih tržišta i različitih oblika finansijskih transakcija, pored ostalih faktora, uslovili su i nove načine izbegavanja ilegalnih novčanih tokova kroz različite oblike prevara. Jedan od najčešćih oblika prevara i sticanja nelegalnih prihoda je pranje novca. U radu je prikazan pregled nekih teorijskih definicija i stavova o suštini ovog oblika prevara. U praksi se koriste različite šeme pranja novca od kojih su neke već prepoznate kao ustaljene i na osnovu njih je izrađena tipologija ovih oblika prevara, ali činjenica je da pranje novca u praksi dobija i nove za sada teško prepoznatljive oblike. Neke od šema iz prakse ilustruju transakcije i poslovne aktivnosti kroz koje se odvija pranje novca. U radu su su prikazane neke od ovih uobičajenih šema u pojedinim sektorima poslovanja.
\end{abstract}

Ključne reči:

prevara, pranje novca, šeme, kriminal.

\section{UVOD}

Globalizacija kao planetarni fenomen i proces znatno je uticao na odvijanje svetskih ekonomskih procesa i rušenje određenih barijera koje su se nalazile na putu implementacije tih procesa. Pored pozitivnih, ali i negativnih efekata ovog procesa, može se reći da su rušenje barijera, razvoj finansijskih tržišta, pojava novih oblika ekonomskih i poslovnih aktivnosti i finansijskih transakcija i drugi elementi procesa globalizacije, doveli i do različitih novih, ali i usavršenijih postojećih oblika prevara. Jedan od najčešćih oblika prevara sa sve većim negativnim efektima je pranje novca. Ovaj, može se reći, fenomen, ima sve veći negativni finansijski uticaj, o čemu govore izveštaji svih relevantnih međunarodnih organizacija. Kako bi se ovaj fenomen dobro upoznao i na osnovu toga sprovela efikasna borba za sprečavanje pranja novca potrebno je proučiti najmanje dve stvari. Prva se odnosi na definisanje pojma pranja novca sa elementima koji ga karakterišu i koji se mogu podvrgnuti uticaju određenih, pre svega državnih organa, imajući u vidu da se radi o nezakonitoj radnji. Definicija ovog pojma mora biti precizna i jasna, a biće takva u onoj meri u kojoj je ovaj problem proučen. Za sada ne postoji jedna opšteprihvaćena definicija, pa je cilj ovog rada da prikaže različite definicije koje odražavaju i različite pristupe u ukazivanju na osnovne karakteristike ovog fenomena. Druga stvar koju treba proučiti jeste na koji način se odvija proces pranja novca. Teorija u tom pogledu ima više saglasnosti nego kada je u pitanju definisanje problema, iako među definicijama postoji određeni stepen saglasnosti. $U$ tom pogledu, sve relevantne međunarodne organizacije koje stoje na putu ovom fenomenu definišu ovaj problem kao i proces odvijanja pranja novca. Značajna karakteristika ovog fenomena je i to što je zahvatio gotovo sve segmente poslovnih aktivnosti tako da gotovo nema privrednog sektora koji nije zahvaćen ovom pojavom. Različiti oblici koje pranje novca dobija i različiti načini na koje se odvija zahtevaju dalju teorijsku, ali i empirijsku pažnju, kako bi se protiv ove pojave vodila efikasna borba. 


\section{NEKE OD DEFINICIJA PRANJA NOVCA}

Kao i mnogi teorijski pojmovi, tako je i pranje novca nastalo najpre u praksi iz aktivnosti klasičnog kriminala. Ova pojava, dakle, nastala je izvorno kao oblik kriminalnih aktivnosti. Interesantan je istorijat nastanka ovog pojma. Opisujući istorijski momenat nastanka pranja novca, Lilley (2006) navodi da je ovaj pojam najverovatnije nastao u Sjedinjenim Američkim Državama 1920-tih godina. Kriminalne organizacije su problem ubacivanja nezakonito stečenog novca u legalne novčane tokove rešavale tako što su preuzimale preduzeća sa velikim gotovinskim novčanim tokovima, kao što su perionice odeće ili perionice kola. Prljavi novac stečen kriminalom, mešan je sa novcem stečenim legalnim poslovanjem perionica i na taj način izlazio kao legalno stečeni prihod. Dakle, sam pojam-termin pranje novca, zaista je u bukvalnom smislu asocijativno povezan sa poslovnom aktivnošću pranja odeće i kola. Tehnike pranja novca, vremenom su se usavršavale onako kako su se razvijali uslovi u kojima je ova vrsta prevare moguća. Disperzija novčanih tokova i mogućnosti za ubacivanje prljavog novca u legalne novčane tokove rasli su paralelno. Danas, gotovo da nema sfere poslovanja u kojoj se na neki način ne odvija i pranje novca. Isti autor, (Lilley, 2006) ističe da je pranje novca dinamičan proces koji omogućava kriminalnim aktivnostima svih vrsta da rastu i da se razvijaju, odnosno, ovaj proces je toliko ugrađen u legalni, normalni posao da su male šanse da se kontroliše, a kamoli da se iskoreni. Po mišljenju Cuéllar M.F. (2003), termin pranje novca postao je prisutan 1980-tih. tokom diskusije o zakonu o drogama i organizovanom kriminalu i izveštaja administracije tadašnjeg predsednika SAD Regana, koji je stavio jak naglasak na uticaj pranja novca kao oblika kriminala. Pranje novca se definiše kao proces kojim se prikriva postojanje nelegalnih izvora ili nelegalnog korišćenje prihoda kako bi se ovako stečeni prihod pojavio kao legalan. Sličnu definiciju daju Gao \& Ye (2007), koji pranje novca definišu kao kriminalni proces u kojim se prikriva poreklo prljavog novca kako bi novac izgledao legitiman i čist. Oblast pranja novca kao pojavnog oblika organizovanog kriminala je relativno novo polje teorijskih istraživanja. Ekonomija pranja novca koja ima za cilj da istraži obim i uticaj nelegalno stečenih sredstava je relativno nova oblast (Walker \& Unger, 2009). Ovi autori navode studiju koju je uradio Friedrich Schneider (Schneider, 2006) i u kojoj je objavio procene u oblasti sive ekonomije za 145 zemalja. Siva ekonomija je definisana kao kao ekonomska aktivnost u zemlji koja je skrivena od vlasti, naročito od poreskih organa (Walker \& Unger, 2009). Teorijsku definiciju pranja novca sa ekonomskog stanovišta uticaja pranja novca u smislu transformacije potencijalne kupovne moći u efektivnu daje Masciandaro (1999), koji navodi da ekonomska funkcija pranja novca zahteva i odgovarajuću definiciju. Definicija ovog pojma u interpretaciji ovog autora struktuirana je na dve ključne karakteristike fenomena pranja novca: nezakonitost pranja novca podrazumeva upotrebu bilo kog prihoda koji potiče iz krivične ili nezakonite aktivnosti i prikrivanje, što podrazumeva aktivnost da se sakrije nelegalni izvor takvih prihoda. Prva karakteristika ukazuje na krivičnu dimenziju pranja novca, dok druga karakteristika ukazuje na pretvaranje nelegalno stečenog prihoda u legalni obzirom da se nelegalno stečeni prihod ne može koristiti za potrošnju, investicije, štednju itd. Poreklo termina pranje novca objašnjavaju i Schneider and Windischbauer (2010), na sličan način kao i Lilley (2006) odnosno ovaj termin potiče iz SAD i objašnjava pokušaj mafije da nelegalno stečeni novac ubaci u legalne tokove preko „salona za pranje“ koji su bili karakteristični po intenzivnim gotovinskim novčanim tokovima, a koje su bile kontrolisane putem kompanijskih akvizicija ili kao poslovne formacije adekvatne tom dobu. Ekonomsko obeležje pranju novca autori daju konstatacijom da ilegalna ekonomska aktivnost obuhvata sve vrste kriminalnih aktivnosti koje su u suprotnosti sa zakonom, a da je dobit koja se ostvaruje kroz ovu ekonomsku (ilegalnu) aktivnost predmet procesa pranja novca. Obim i novčani uticaj ove nezakonite aktivnosti meri se u nekim studijama iznosima od 400 milijardi do 2,85 biliona USD (u originalnom američkom nominalnom izrazu: 400 billion to 2,85 trillion USD), (Schneider \& Windischbauer, 2010). Tehnike skrivanja prihoda koji potiče iz kriminalnih aktivnosti uključuju: prebacivanje novca iz zemlje za kupovinu preduzeća u inostranstvu, preko kojih sredstva mogu biti kanalisana u legalne tokove, kupovina lako prenosivih dragocenosti, transferne cene i korišćenje "podzemnih banaka” (Levi \& Reuter, 2006). Novac može da bude prljav na dva načina. Jedan od načina je utaja poreza kod koje se zaradi više nego što se prijavi poreskim organima. Novac može biti prljav ako je generisan kroz ilegalne-nezakonite aktivnosti (prodaja droge, kocka, prevare). Kada je novac prljav mora se pretvoriti u prividno legitiman oblik, mora da se opere pre nego što se uloži ili potroši. Pranje novca je proces kojim se prikriva postojanje nelegalnog izvora kako bi se pojavio legitimni prihod (Welling, 1989). Investopedija definiše pranje novca kao proces stvaranja utiska da velike sume novca koje potiču iz teških krivičnih dela kao što su trgovina drogom ili terorističke aktivnosti potiču iz legitimnih izvora.

Pranje novca je globalni ekonomski problem. Suočavanje sa ovim problemom nije samo u domenu teorije već $\mathrm{i} u$ domenu prakse. Međunarodne organizacije, zakonodavstvo i drugi oblici regulative takođe se bave definisanjem pojma pranja novca.

Jedna od najaktivnijih organizacija u borbi protiv pranja novca je Financial Action Task Force (FATF). Ova organizacije definiše pranje novca kao proces postupanja sa sredstvima stečenim kriminalnim radnjama kako bi se sakrilo njihovo poreklo. Ovaj proces (prikrivanja) je od ključnog značaja, jer omogućava kriminalcima da koriste tako ostvareni profit bez ugrožavanja njegovog izvora. Evropska unija takođe pridaje veliki značaj pranju novca kao negativnoj i štetnoj pojavi. U svojoj direktivi (91/308/EEC) pranje novca definiše detaljno u postupcima i radnjama koja su obeležja ovog krivičnog 
dela. Pranje novca podrazumeva sledeće aktivnosti koje su učinjene sa namerom: a) konverzija ili transfer imovine, sa saznanjem da takva imovina potiče od kriminalne aktivnosti ili od učestvovanja u takvoj aktivnosti sa ciljem prikrivanja nezakonitog porekla imovine ili pomaganje nekom licu koje je uključeno u takve aktivnosti kako bi se izbegle zakonske posledice takvog delovanja; b) prikrivanje ili netačno prikazivanje prave prirode, izvora, lokacija, raspolaganja, kretanja, prava u odnosu na vlasništvo te imovine, znajući da ta imovina potiče od kriminalne aktivnosti ili od učestvovanja u toj aktivnosti; c) sticanje, posedovanje ili korišćenje imovine, znajući u trenutku prijema da takva imovina potiče od kriminalne aktivnosti ili od učestvovanja u njoj; d) učešće i udruživanje radi vršenja, pokušaja vršenja i pomaganja, podsticanja, olakšavanja i savetovanja u vezi izvršenja bilo koje radnje navedene u prethodnim stavovima. Ujedinjene nacije i Međunarodni monetarni fond definišu pranje novca slojevito i detaljno. United Nations Office on Drugs and Crime (UNODC) i International Monetary Fund (IMF), definišu pranje novca na isti način kako je to definisano i Direktivom Evropskog saveta (UNODC \& IMF, 2005). Međunarodni monetarni fond definiše pranje novca kao proces kojim se krije veza između nedozvoljenih izvora i sredstava koja su generisana iz tih izvora odnosno kriminalnih aktivnosti (IMF, 2016). Interpol kao međunarodna kriminalistička policijska organizacija pranje novca definiše kao svaki akt ili pokušaj vršenja akta prikrivanja nezakonito stečenih sredstava tako da se stvori privid da su ta sredstva iz legitimnih izvora. Varšavska konvencija (2005), usvaja definiciju pranja novca po ugledu na Direktivu Saveta Evrope. U našem zakonodavstvu, ova konvencija je usvojena zakonom u celini. Domaće zakonodavstvo definiše pranje novca u dva osnovna zakona. U Zakonu o sprečavanju pranja novca i finansiranja terorizma pranjem novca smatra se: a) konverzija ili prenos imovine stečene izvršenjem krivičnog dela; b) prikrivanje ili netačno prikazivanje prave prirode, porekla, mesta nalaženja, kretanja, raspolaganja, vlasništva ili prava u vezi sa imovinom koja je stečena izvršenjem krivičnog dela; c) sticanje, držanje ili korišćenje imovine stečene izvršenjem krivičnog dela. Krivičnim zakonikom Republike Srbije pranjem novca smatra se da ko izvrši konverziju ili prenos imovine, sa znanjem da ta imovina potiče od krivičnog dela, u nameri da se prikrije ili lažno prikaže nezakonito poreklo imovine, ili prikrije ili lažno prikaže činjenice o imovini sa znanjem da ta imovina potiče od krivičnog dela, ili stekne, drži ili koristi imovinu sa znanjem, u trenutku prijema, da ta imovina potiče od krivičnog dela, kazniće se zatvorom od šest meseci do pet godina i novčanom kaznom. Obzirom da se radi o zakonskoj odredbi zaprećena je i kazna za izvršenje ovog krivičnog dela.

\section{EMPIRIJSKE ŠEME PRANJA NOVCA}

Proces pranja novca prolazi kroz tri faze: ulaganje, raslojavanje i integracija. Svaka od ovih faza ima svoj cilj a svi ciljevi su na kraju integrisani u opšti cilj a to je prikaz nelegalno stečenog novca kao legalnog i njegovo dalje korišćenje u privrednim aktivnostima ili ličnoj potrošnji. U Tipologiji pranja novca u Srbiji koju je izradila Uprava za sprečavanje pranja novca i finansiranja terorizma, opisan je proces pranja novca $\mathrm{u}$ ove tri faze na sledeći način:

1. Prva faza je faza ulaganja kojom se prekida direktna veza između novca i nezakonite aktivnosti kojom je stečen. U ovoj fazi, prljav novac se uvodi u finansijski sistem najčešće u vidu neke zakonite aktivnosti u kojoj se plaćanje vrši gotovim novcem. Jedan od najčešćih načina koji je uočen je osnivanje fiktivnog privrednog društva koje nema poslovnih aktivnosti već služi samo za polaganje prljavog novca ili za usitnjavanje velikih suma. Cilj ove aktivnosti je ubacivanje novca u legalan finansijski sistem.

2. Druga faza je faza raslojavanja ili prikrivanja koja se odvija nakon što je novac ušao u legalni finansijski sistem. U ovoj fazi se vrši prebacivanje novca sa računa na koji je položen na druge račune privrednih društava. Cilj ovih transfera je da se prikaže fiktivna poslovna aktivnost ili da se obavi neki zakonit posao sa privrednim društvom koje legalno posluje. Cilj ove aktivnosti je prikrivanje veze između novca i nezakonite aktivnosti iz koje je novac stečen.

3. Treća faza je faza integracije, u kojoj se prljav novac pojavljuje kao novac koji je stečen iz legalne aktivnosti. Česti metodi integracije su kupovina nekretnina ili kupovina kontrolnog paketa akcija akcionarskih društava. Ova aktivnost predstavlja koncentraciju prljavog novca velikih razmera što je i cilj onih koji se bave ovom nezakonitom radnjom. Integracija se koncentriše na tržište, odnosno na ono što se može kupovati i prodavati a da predstavlja zakonit posao. Čest primer je davanje nekretnina u zakup što predstavlja zakonit prihod. Zatim, integracija može da se sprovede i prema privrednom društvu koje je u teškoćama i koje posle priliva svežeg kapitala počinje da posluje dobro pri čemu je dobit iz poslovanja zakonit prihod. U ovoj fazi je teško otkriti nezakonito poreklo novca što je i osnovni cilj ove faze. Proces pranja novca prikazan je slikom 1.

Proces pranja novca odvija se u svim sektorima poslovnih aktivnosti. Ovaj sistem je razrađen u meri da se mnogobrojne organizacije i državni organi bore protiv ove pojave širom sveta. U narednom delu teksta biće prikazane šeme pranja novca u Srbiji prema Tipologiji šema pranja novca. Ove šeme su uočene kao pravilo pa se na osnovu toga i govori o tipologiji. Dokument koji je uzet kao osnova prikaza šema pranja novca izrađen je na preporuku FATF kako bi se borba protiv ovog problema odvijala efikasno.

U daljem tekstu će biti prikazani slučajevi iz prakse u Srbiji, a na osnovu izveštaja Uprave za sprečavanje pranja novca 


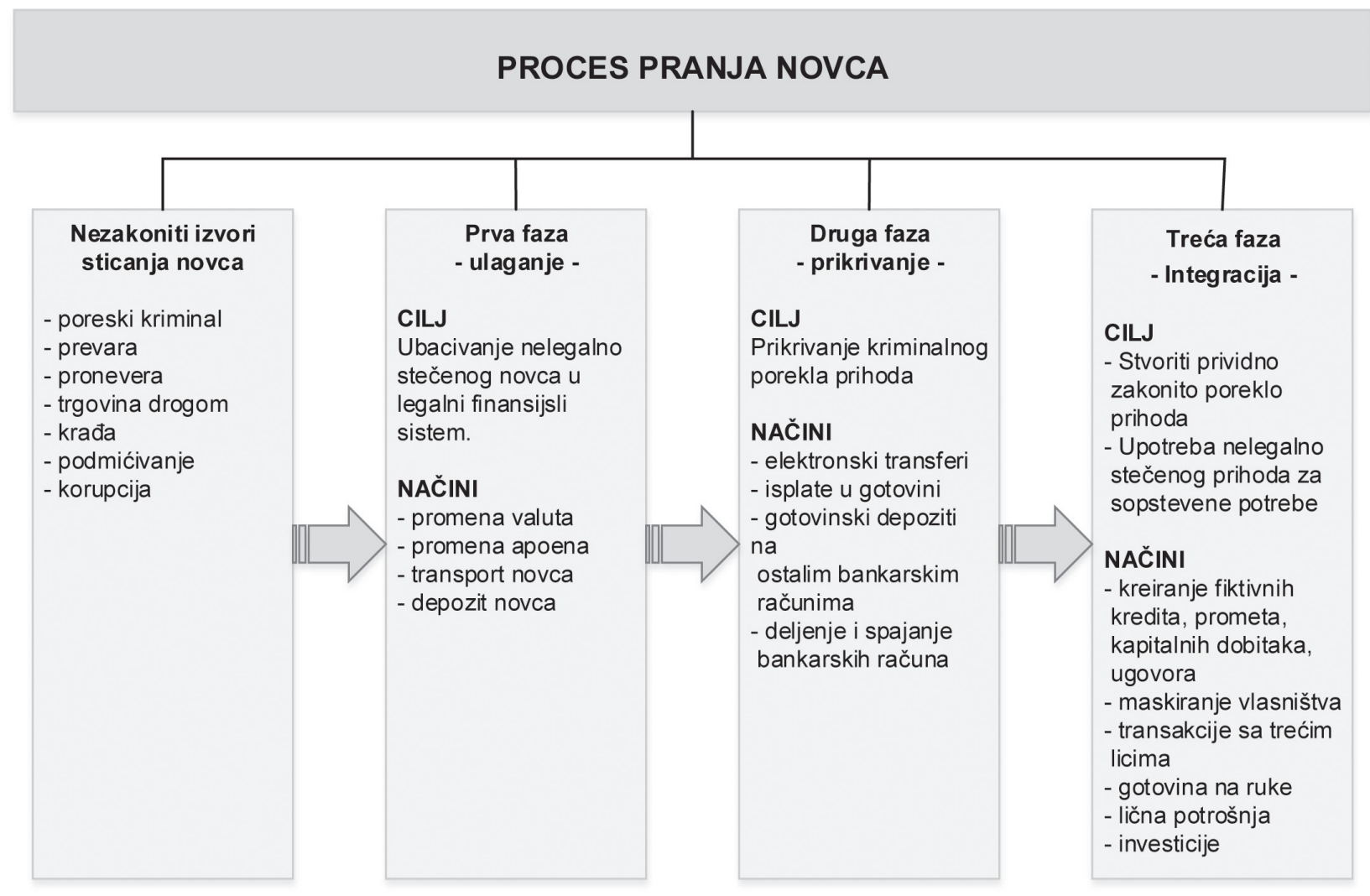

Slika 1: Proces pranja novca

Izvor: OECD (2009)

(USPNFT, 2015). Obzirom da je otkrivanje, istraga i procesuiranje ovih oblika kriminala zadatak nadležnih državnih organa, izvori u kojima su opisani ovi slučajevi dostupni su jedino iz dokumenata ovih organa. U šemama su učesnici ovog slučaja pranja novca navedeni pod šiframa. USPNFT je izradila i Tipologiju pranja novca u Republici Srbiji, kao opšte obrasce na osnovu više puta ponovljenih načina pranja novca koji su sličnih ili dovoljno sličnih karakteristika na osnovu kojih se izrađuju tipologije, što je inače jedna od međunarodnih obaveza ove uprave na osnovu preporuka FATF.

\section{Slučaj 1. Integracija prljavog novca kroz uplate} pozajmica i zajmova

Fizičko lice " $\mathrm{X}$ " koje je više puta pravosnažno osuđivano za različita krivična dela, gotovinski polaže sredstva u iznosu od 70.000.000 RSD na račun pravnog lica "A" koje je u njegovom vlasništvu. Sredstva su položena po osnovu pozajmice osnivača za likvidnost. Manji deo položenih sredstava u iznosu od 10.000.000 RSD, vraća se vlasniku na osnovu povraćaja pozajmice dok se ostatak sredstava u iznosu od 60.000 .000

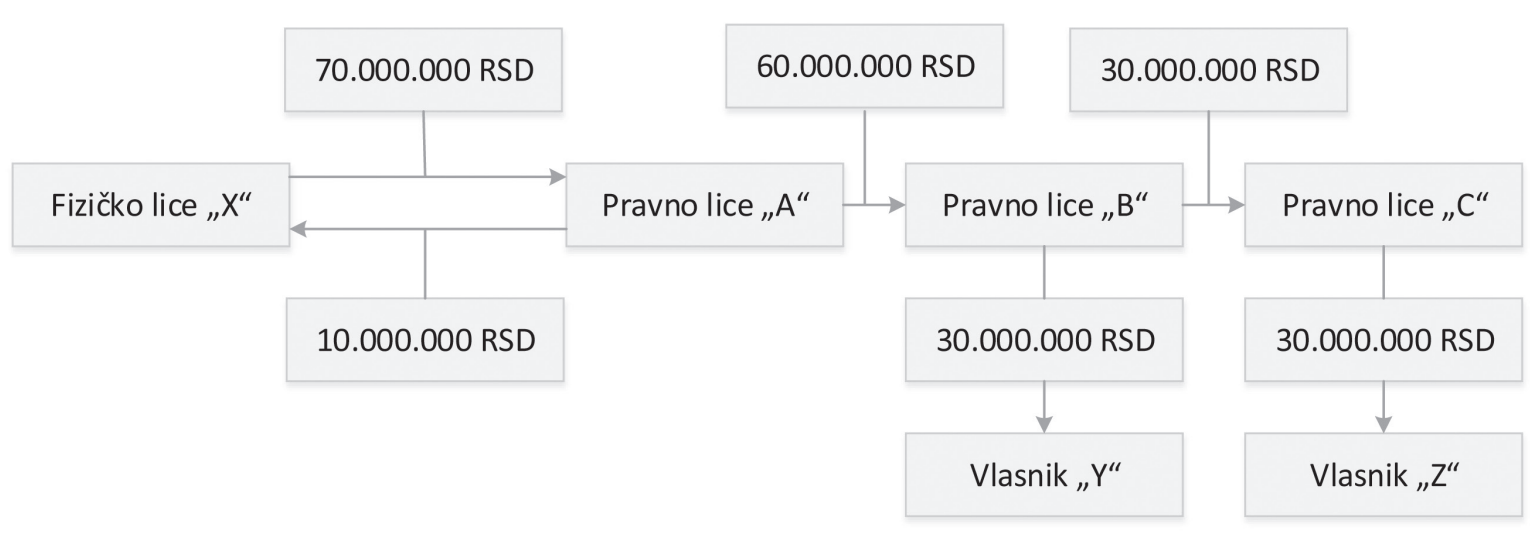

Šema 2: Integracija prljavog novca kroz uplate pozajmica i zajmova, Izveštaj USPNFT za 2015. 
RSD transferiše na račun pravnog lica "B" po osnovu zajma. Polovinu transferisanih sredstava u iznosu od 30.000.000 RSD podiže u gotovini vlasnik (Y) pravnog lica "B" po osnovu zajma, a druga polovina sredstava u iznosu od 30.000 .000 RSD transferiše se na račun pravnog lica "C" po osnovu prometa robe i usluga. Transferisana sredstva u iznosu od 30.000.000 podiže vlasnik (Z) pravnog lica "C". Može se pretpostaviti da su vlasnici "Y" i " $Z$ " povezana lica licem " $X$ " $i$ da su podignuta sredstva sa računa pravnih lica "B" $i$ " $C$ " prosleđena fizičkom licu "X". Nakon obavljene analize USPN je informacije dostavila tužilaštvu i poreskoj upravi koja je obavila kontrolu i podigla krivične prijave. Ovaj slučaje je ilustrovan Šemom 2.

\section{Slučaj 2: Neosnovano dobijanje kredita}

USPNFT je primila sumnjiv izveštaj banke. U vremenskom periodu od oko dve godine, većem broju fizičkih lica odobreni su gotovinski krediti ukupne vrednosti od RSD 29.000.000. Analiza kreditne dokumentacije pokazala je da je većina korisnika kredita zaposlena u verskoj zajednici „A“, na poslovima vozača, kuvara i sl. a visina primanja im je iznad proseka u Republici Srbiji. Uočeno je kašnjenje otplate kre- dita ovih korisnika. Otplatu kredita po svim odobrenim kreditima vrši visokopozicionirano lice u verskoj zajednici „B“. UPSPNFT ne raspolaže informacijama o poreklu sredstava kojima fizičko lice „B“ otplaćuje kredite drugim fizičkim licima korisnicima kredita. Iskazana je sumnja u legalnost izvora sredstava koja fizičko lice „B“ koristi za otplatu kredita kao i sumnja da fizičko lice „B“ falsifikuje dokumenta kako bi obezbedio kredite, a da sredstva koristi za svoje lične potrebe ili u korist verske zajednice. Iz navedenih informacija osnovana je sumnja da je u pitanju krivično delo neosnovano dobijanje i korišćenje kredita i drugih pogodnosti. Ovaj slučaj prikazan je na Šemi 3.

\section{Slučaj 3: Integrisanje i raslojavanje nelegalnog novca u novčane tokove}

USPNFT primila je više sumnjivih izveštaja poslovne banke. Pravno lice „A“ sa Kipra je vlasnik pravnog lica “ $B$ “ u Srbiji. Krajnji vlasnik pravnog lica „A“ sa Kipra, kao i zakonski zastupnik pravnog lica „B“ je fizičko lice „X“. Pravno lice „A“ sa Kipra je 62\% vlasnik pravnog lica „C“ u Srbiji. Sa računa pravnog lica „A“ sa Kipra transferišu se sredstva na

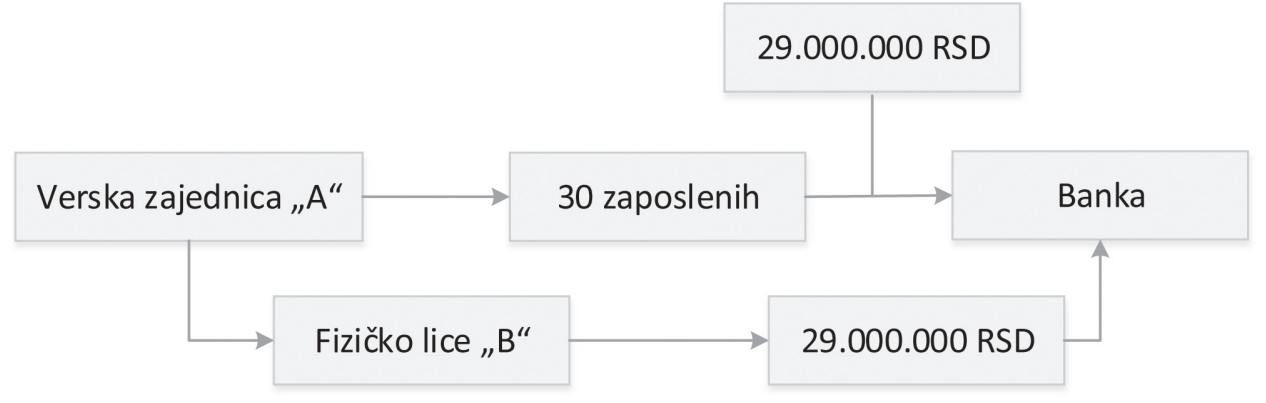

Šema 3: Neosnovano dobijanje kredita, Izveštaj USPNFT za 2015. 
račun pravnog lica „B“ u iznosu od EUR 100.000 po osnovu Ugovora o zajmu, koji ne povećava osnovni kapital. Sutradan se sredstva transferišu na račun pravnog lica „C“ u iznosu od RSD 12.025.140 po osnovu ugovora o zajmu. Uprava je izrazila sumnju da se tokovima novca pravnih lica koja su povezana vlasničkom i upravljačkom strukturom, nelegalno stečen novac integriše a zatim raslojava u legalne novčane tokove. Ovaj slučaj prikazan je u Šemi 4.

$\mathrm{U}$ šemama pranja novca koje su prikazane vidi se samo deo brojnih kombinacija i šema koje su prisutne u praksi Srbije. Ove šeme su urađene kao tipološke, što znači da se mogu posmatrati i kao šeme koje se primenjuju i van naših granica. Razvoj tržišta i otvaranje mnogobrojnih različitih poslovnih aktivnosti je dobar ambijent za razvoj ekonomije, ali na žalost isti ti pozitivni faktori uticaja na razvoj otvaraju i brojne mogućnosti za pranje novca.

\section{ZAKLJUČAK}

Pranje novca je postao globalni fenomen sa brojnim varijacijama. Imajući u vidu kompleksnost ovog pojma, definicije koje se navode u literaturi obuhvataju različite elemente. Međutim, može se zaključiti da postoji nekoliko elemenata koji su imanentni gotovo svim navedenim definicijama. Pranje novca je pre svega nezakonita radnja, pa i stečeni novac na ovaj način je nezakonito stečen novac. Osnovni cilj perača novca je da nelegalno stečeni novac ubace u legalni finansijski sistem kako bi prikrili nezakonito poreklo novca. Daljim transakcijama ovaj novac dobija legitimitet, jer se ulaže u legalne poslove a dobit iz tih poslova postaje legalna dobit koja se može dalje ulagati u zakonite i legalne poslove. U ovoj fazi je veoma teško otkriti poreklo novca. Proces pranja novca je strukturiran u tri faze i u tom pogledu u teoriji postoji saglasnost. Međutim, bez obzira što je proces pranja novca razotkriven kroz faze kroz koje prolazi i dalje je teško dokazati nezakonito poreklo novca ukoliko se to ne učini u početnoj fazi. Borba protiv pranja novca je postala globalna borba koja zahteva punu saradnju zemalja i državnih organa u toj borbi. U tom smislu su sve relevantne međunarodne organizacije donele određena dokumenta u kojima je definisan pojam pranja novca skoro na istovetan način što očito govori o saglasnosti oko sadržine i karakteristika ovog problema. Međutim, ovaj fenomen dobija sve novije oblike, tako da će međunarodna zajednica, a i sve države ponaosob morati da ulože još mnogo napora kako bi se ovaj problem ublažio ako već postoji sumnja da ga je nemoguće iskoreniti.

\section{LITERATURA}

Cuéllar, M.F. (2003). The Tenuous Relationship between the Fight against Money Laundering and the Disruption of Criminal Finance. Journal of Criminal Law and Criminology, 93(2/3), 311- 465.
EUR-lex. (1991). Council Directive 91/308/EEC of 10 June 1991 on prevention of the use of the financial system for the purpose of money laundering, Official Journal L 166 , 28/06/1991 P. 0077 - 0083. Preuzeto 12. Maja 2016. sa http://eur-lex. europa.eu/legal-content/SK/ALL/?uri=CELEX:31991L0308

FATF. (2016). What is Money Laundering. Preuzeto 12. Maja 2016. sa http://www.fatf-gafi.org/faq/moneylaundering/\#d. en. 11223

Gao, Z., \& Ye, M. (2007). A framework for data mining-based antimoney laundering research. Journal of Money Laundering Control, 10(2), 170-179.

International Monetary Fund. (2016). A Fact sheet :The IMF and the Fight Against Money Laundering and the Financing of Terrorism. Preuzeto 12. Maja 2016. sa http://www.imf.org/en/ About/Factsheets/Sheets/2016/08/01/16/31/Fight-AgainstMoney-Laundering-the-Financing-of-Terrorism

Interpol. (2016). Money-laundering. Preuzeto 12. maja 2016. sa http://www.interpol.int/Crime-areas/Financial-crime/ Money-laundering

Investopedia. (2016). Money Laundering Definition. Preuzeto 12. Maja 2016. sa http://www.investopedia.com/terms/m/moneylaundering.asp

Levi, M. \& Reuter, P. (2006). Money laundering. Crime and Justice, $34(1), 289-375$.

Lilley, P. (2006). Dirty dealing: The untold truth about global money laundering, international crime and terrorism. London: Kogan Page Publishers.

Masciandaro, D. (1999). Money laundering: the economics of regulation. European Journal of Law and Economics, 7(3), 225-240.

OECD. (2009). Money Laundering Awareness Handbook for Tax Examiners and Tax Auditors. Preuzeto 12. Maja 2016. sa https:// www.oecd.org/tax/exchange-of-tax-information/43841099.pdf

Schneider, F., \& Windischbauer, U. (2010). Money Laundering: Some Facts. Economics of Security Working Paper 25, Berlin: Economics of Security.

Službeni glasnik Republike Srbije. (2005). Krivični zakonik. Sl. glasnik RS”, br. 85/2005, 88/2005 - ispr., 107/2005 - ispr., 72/2009, 111/2009, 121/2012, 104/2013 i 108/2014.

Službeni glasnik Republike Srbije. (2009). Zakon o potvrđivanju konvencije Saveta Evrope o pranju, traženju, zapleni i oduzimanju prihoda stečenih kriminalom i o finansiranju terorizma. Sl. glasnik RS - Međunarodni ugovori, br. 19/2009.

Službeni glasnik Republike Srbije. (2014) . Zakon o sprečavanju pranja novca i finansiranja terorizma. Službeni glasnik RS, br. 20/2009, 72/2009, 91/2010 i 139/2014.

UNODC, IMF (2005). Model Legislation on Money Laundering and Financing of Terrorism. Preuzeto 12. Maja 2016. sa https://www.unodc.org/unodc/en/money-laundering/ Model-Legislation.html

Uprava za sprečavanje pranja novca Republike Srbije. (2011). Tipologije pranja novca u Republici Srbiji. Preuzeto 12. Maja 2016. sa http://www.apml.gov.rs/REPOSITORY/976_tipologije-pranja-novca-u-republici-srbiji13-09-2011-cir.pdf 
Walker, J., \& Unger, B. (2009). Measuring global money laundering: The Walker gravity model. Review of Law and Economics, 5(2), 821-853. doi: 10.2202/1555-5879.1418.

Welling, S.N. (1989). Smurfs, Money Laundering and the Federal Criminal Law: The Crime of Structuring Transactions. Florida Law Review, 41(2), 287-343.

\section{DEFINITIONS AND EMPIRICAL MONEY LAUNDERING SCHEMES}

\section{Abstract:}

An accelerated economic development, an introduction of new information-communication technologies, a development of financial markets, and various forms of financial transactions, among other factors, have conditioned the new manners of avoiding illegal cash flows through various forms of frauds. One of the most common forms of frauds and gaining of illegal profit is money laundering. The paper presents an overview of some theoretical definitions and attitudes regarding the essence of this form of frauds. In practice, various money laundering schemes are used, out of which some are recognised as settled, and based on them the typology of these forms of frauds has been made, but it is a fact that money laundering in practice gains new and currently hardly recognisable forms. Some of the schemes from the practice illustrate the transactions and business activities through which money laundering takes place. The paper presents some of these usual schemes in some business sectors.

\section{Keywords:}

fraud,

money laundering,

schemes,

crime. 